semi-intact cells. VGMs appear dispersed throughout the cytoplasm following IQ treatment, while stacks appear as large discrete aggregates by immunofluorescence in intact cells after removal of IQ $[12,13]$. This assay exploits the ability to distinguish the relative distribution of VGMs and the stacks of Golgi cisternae by immunofluorescence microscopy using Golgi-specific antibodies. Electron microscopy has been used to confirm that the large aggregates of Golgi membranes are indeed stacks of cisternae. This assay is quantitative and relatively simple, and therefore provides a unique opportunity to identify the cytoplasmic proteins that catalyse the fusion and assembly of VGMs into stacks of cisternae [20].

The effects of IQ on the organization of Golgi stacks in whole cells mimic the dynamics of Golgi membranes seen in association with the events of the cell cycle. It is likely, therefore, that proteins identified from this assay using IQ as an inhibitor of stack formation will help our understanding of the process by which Golgi stacks are assembled and the mechanism by which their organization is regulated during the cell cycle.

This work was supported by a Basil O'Connor starters scholar's award from the March of Dimes Birth Defect Foundation and NIH grant GM46224 to V.M.

1 Rogalski, A. A. and Singer, S. J. (1984) J. Cell Biol. 99 , 1092-1100

2 Ho, W. C., Allan, V. J., van Meer, G., Berger, T. E. and Kreis, T. E. (1989) Eur. J. Cell Biol. 48, 250-263

3 Kreis, T. E. (1990) Cell. Motil. Cytoskeleton 15, $67-70$
4 Corthésy-Theulaz, I., Pauloin, A. and Pfeffer, S. R (1992) J. Cell Biol. 118, 1333-1345

5 Cooper, M. S., Cornell-Bell, A. H., Chernjavski, A., Dani, J. W. and Smith, S. J. (1990) Cell 61, 135-145

6 Rothman, J. E. and Warren, G. (1994) Curr. Biol. 4, 220-233

7 Pryer, K. N., Wuestehube, L. J. and Schekman, R. (1992) Annu. Rev. Biochem. 61, 471-516

8 Rothman, J. E. and Orci, L. (1992) Nature (London) 355, 409-415

9 Lucocq, J. M., Pryde, J. G., Berger, E. G. and Warren, G. (1987) J. Cell Biol. 104, 865-874

10 Lucocq, J. M., Berger, E. G. and Warren, G. (1989) J. Cell Biol. 109, 463-474

11 Warren, G. (1993) Annu. Rev. Biochem. 62, 323-348

12 Takizawa, P. A., Yucel, J. K., Veit, B. et al. (1993) Cell 73, 1079-1090

13 Veit, B., Yucel, J. K. and Malhotra, V. (1993) J. Cell Biol. 122, 1197-1206

14 Waters, M. G., Serafini, T. and Rothman, J. E. (1991) Nature (London) 349, 248-251

15 Duden, R., Griffiths, G., Frank, R., Argos, P. and Kreis, T. E. (1991) Cell 64, 649-665

16 Lippincott-Schwartz, J., Donaldson, J. G., Schweizer, A. et al. (1990) Cell 60, 821-836

17 Klausner, R. D., Donaldson, J. G. and LippincottSchwartz, J. (1992) J. Cell Biol. 116, 107-1080

18 Alcalde, J., Bonay, P., Roa, A., Vilaro, S. and Sandoval, I. V. (1992) J. Cell Biol. 116, 69-83

19 Karecla, P. I. and Kreis, T. E. (1992) Eur. J. Cell Biol. 57, 139-146

20 Acharya, U., Jacobs, R., McCaffery, M. J. and Malhotra, V. (1995) J. Cell Biol. 129, 577-589

Received 8 March 1995

\title{
Recycling of the endoplasmic reticulum/Golgi intermediate compartment protein ERGIC-53 in the secretory pathway
}

C. Itin*, M. Foguet*, F. Kappeler*, J. Klumpermant and H.-P. Hauri*ł

*Department of Pharmacology, Biozentrum, University of Basel, CH-4056 Basel, Switzerland, and +Faculty of Biology, Vrije Universiteit Amsterdam, NL-108I HV Amsterdam, The Netherlands

\section{Introduction}

Although it has been appreciated for quite some time that anterograde and retrograde membrane traffic in the secretory pathway must be precisely balanced to ensure the integrity of each organelle,

Abbreviations used: ER, endoplasmic reticulum; ERGIC, $\mathrm{ER} /$ Golgi intermediate compartment; COP, coat protein of non-clathrin-coated vesicles.

$\ddagger$ To whom correspondence should be addressed. little is known about the routes or the mechanism of retrograde traffic. This is mainly due to insufficient knowledge of the compartmental organization of the secretory pathway and the paucity of identified constitutively recycling reporter proteins. We have identified and characterized such a protein, termed ERGIC-53, from human cells [1,2].

ERGIC-53 is a non-glycosylated homodimeric and homohexameric type 1 membrane protein with putative lectin function [3]. Antibodies to 
ERGIC-53 and its presumed rat homologue p58 [4] preferentially label characteristic tubulo-vesicular clusters near the cis-side of the Golgi apparatus, but also label those further out in the cell periphery [1]. We refer to these structures as the endoplasmic reticulum (ER)/Golgi intermediate compartment (ERGIC) [5]. The ERGIC defined by protein ERGIC-53 is the site where ER-to-Golgi transport of vesicular stomatitis virus $G$ protein is blocked at $15^{\circ} \mathrm{C}[6,7]$. It can be identified independently by antibodies against the small GTPase rab2 [8] and the coat protein $\beta$-COP is also largely associated with the ERGIC $[9,10]$. Biochemical analysis with Vero cells showed that the ERGIC is little related to its neighbouring organelles, the rough ER and cisGolgi [11]. The putative target receptor (t-SNARE) sed $5 /$ syntaxin 5 is also largely associated with these membranes, suggesting that the ERGIC is the first post-ER compartment [12]. However, the functions of the ERGIC have not been identified [13].

ERGIC-53/p58 is not exclusively restricted to the ERGIC but is occasionally seen in the first fenestrated cis-cisterna of the stacked Golgi $[1,8]$ and in the ER [14], suggesting the presence of a recycling pathway. In the present studies we have used morphological and subcellular fractionation approaches to establish the recycling pathway of ERGIC-53 and to study biochemical requirements for retrograde protein transport. Moreover, we have identified the signals that target ERGIC-53 to the ER/ERGIC/cis-Golgi recycling pathway.

\section{Morphological analysis of recycling}

The subcellular distribution of ERGIC-53 is affected by temperature manipulations. Analysis by immunofluorescence microscopy shows progressive concentration of ERGIC-53 in the Golgi areas of cells cultured at $15^{\circ} \mathrm{C}[6,15]$. Upon rewarming to $37^{\circ} \mathrm{C}$, ERGIC-53 redistributes to tubular processes emanating from the Golgi region into the cell periphery and subsequently assumes an ER-like pattern. Immunoelectron microscopy of HepG2 cells revealed the concentration to be due to two events: movement of ERGIC clusters closer to the Golgi apparatus and accumulation of ERGIC-53 in the clusters. The temperature manipulations had no effect on the average number of ERGIC clusters, nor was there any evidence for fusion of the clusters with the stacked Golgi upon rewarming. Collectively, this analysis suggests that the ERGIC is a dynamic membrane system composed of a constant average number of tubulo-vesicular clusters. The major recycling pathway of ERGIC-53 from the ERGIC to the ER bypasses the Golgi apparatus and involves membrane tubules emanating from ERGIC clusters.

\section{Biochemical analysis of recycling}

To study the recycling of ERGIC-53 in more detail, we have developed a Nycodenz density-gradient method that allows the separation of the ER, ERGIC and cis/medial-Golgi membranes from HepG2 cells. ER membranes were identified by measuring glucose-6-phosphatase activity, and by immunoblotting with antibodies against protein disulphide isomerase (kindly provided by $\mathrm{Dr} \mathrm{S}$. Fuller, Heidelberg, Germany), epoxide hydrolase and ribophorin I (kindly provided by Dr D. Meyer, Los Angeles, CA, U.S.A.). The cis-Golgi was identified by measuring UDP-GaINAc:polypeptide $N$ acetylgalactosaminyltransferase activity (kindly assayed by Dr H. Clausen, Copenhagen, Denmark) and by immunoblotting with a monoclonal antibody against the KDEL receptor (kindly provided by $\mathrm{Dr}$ B. L. Tang and Dr W. Hong, Singapore). On this gradient, cis-Golgi membranes co-distributed with the medial-Golgi marker A1/118 antigen [16].

ERGIC-53 appeared in three peaks: one comigrating with the $\mathrm{ER}$, one co-migrating with the cis/medial-Golgi and a third peak identified as the ERGIC. Recycling of ERGIC-53 was inhibited in the ERGIC fraction by $15^{\circ} \mathrm{C}$, brefeldin $\mathrm{A}$ or $\mathrm{AIF}_{4}{ }^{-}$. ATP depletion concentrated the protein in the ER, and nocodazole had no effect on the steady-state distribution of ERGIC-53. Synchronized release of ERGIC-53 from the ERGIC after $\mathrm{AIF}_{4}{ }^{-}$washout and from the ER by $\left[{ }^{35} \mathrm{~S}\right]$ methionine pulse-chase revealed two recycling pathways to the $\mathrm{ER}$, one from the ERGIC without prior transport to the cisGolgi and one from cis-Golgi that probably involves passage through the ERGIC. Both pathways are different from that followed by Golgi resident proteins, such as UDP-GaINAc:polypeptide $\mathrm{N}$-acetylgalactosaminyltransferase, A1/118 antigen, giantin [16] and galactosyltransferase, in brefeldin A-treated cells which bypass the ERGIC and accumulate in the ER. As an exception, the KDEL receptor was found to redistribute from the cisGolgi to the ERGIC in response to brefeldin A. The individual retrograde and anterograde transport steps exhibited distinct biochemical requirements, suggesting mechanistic differences. The requirements for exit from the ERGIC, in both the retrograde and anterograde directions, are compatible with COP-mediated vesicular transport, while those for ER-to-ERGIC transport are not. 


\section{Targeting of ERGIC-53 to the ER/ ERGIC/cis-Golgi recycling pathway}

The unique cycling behaviour of ERGIC-53 has prompted us to identify the targeting signals of this protein. An $\mathrm{N}$-glycosylated myc-tagged variant of ERGIC-53 was constructed, mutated and expressed in COS cells. By monitoring endoglycosidase $\mathrm{H}$ resistance the loss of ERGIC-53 from the ER/ ERGIC/cis-Golgi cycle was measured. Domain swapping experiments with the plasma membrane protein CD 4 showed that transmembrane and the luminal domains were not sufficient, while the cytoplasmic domain of ERGIC-53 was required and sufficient for pre-medial-Golgi localization. However, a chimaera composed of a CD4 luminal domain, a CD 4 transmembrane domain and an ERGIC-53 cytoplasmic domain accumulated in the $\mathrm{ER}$, indicating that the cytoplasmic domain is not sufficient for correct targeting. Dissection of the cytoplasmic domain revealed a $\mathrm{C}$-terminal di-lysine ER retrieval signal, KKFF, and an RSQQE targeting determinant adjacent to the transmembrane domain. Surprisingly, the two C-terminal phenylalanine residues were found to influence the targeting by interfering with both the di-lysine ER retrieval signal and the RSQQE determinant. Correct localization of ERGIC-53 requires the cytoplasmic domain comprising the RSQQE determinant, the di-lysine ER retrieval signal and the terminal phenylalanines. Moreover, the presence of the luminal domain is also required, perhaps reflecting a need for proper oligomerization. The precise role of the different signals can now be determined by subcellular fractionation of cells expressing the different ERGIC-53 mutants.

\section{A novel endocytosis signal closely related to the KKXX ER retrieval signal}

In contrast to ER proteins carrying a di-lysine ER retrieval signal, the retention of ERGIC-53 in the pre-medial-Golgi recycling pathway is saturable by overexpression in various cells, leading to partial mistargeting to the cell surface. Cell-surface ERGIC-53 is rapidly endocytosed [17]. Surprisingly, the minimal consensus sequence for endocytosis determined by substitutional mutagenesis ( $\mathrm{KK} / \mathrm{RF} / \mathrm{YF} / \mathrm{Y})$ is related to the ER retrieval consensus sequence (KKXX). The endocytosis signal contains three features: position-dependence from the $\mathrm{C}$-terminus, aromatic residues in positions -1 and -2 , and lysines or arginines in positions -3 and -4 [18]. These features distinguish the
ERGIC-53 endocytosis signal from previously defined mammalian endocytosis signals $[19,20]$.

We have also provided evidence that internalization of VIP 36 [21] is mediated by a signal at its $\mathrm{C}$-terminus that matches the internalization consensus sequence. This suggests that the ERGIC-53 internalization signal belongs to a new class of internalization signals. The relatedness of the novel endocytosis signal and the KKXX ER retrieval signal suggests that coatomer-mediated retrieval [22] may be mechanistically more related to clathrin-dependent sorting than previously anticipated. It is currently unknown whether ERGIC-53, once mistargeted to the cell surface, can recycle again to the secretory pathway.

\section{Conclusions}

In summary, our studies favour the notion of a permanent, albeit highly dynamic, ERGIC. Protein recycling to the $\mathrm{ER}$ can occur from at least two sites, the ERGIC and the cis-Golgi. We propose a counter-current model of ER-to-cis-Golgi anterograde and cis-Golgi-to-ER retrograde traffic through the ERGIC. A complex interplay of multiple signals is required for correct targeting of ERGIC-53 to the pre-medial-Golgi recycling pathway. Experiments aimed at elucidating the retention/recycling machinery for ERGIC-53 are now in progress in our laboratory.

This work was supported by grants from the Swiss National Science Foundation, the Kantons of Basel, and Sandoz Pharma Ltd., Basel.

1 Schweizer, A., Fransen, J. A. M., Bächi, T., Ginsel, L and Hauri, H.-P. (1988) J. Cell Biol. 108, 1643-1653

2 Schindler, R., Itin, C., Zerial, M., Lottspeich, F. and Hauri, H.-P. (1993) Eur. J. Cell Biol. 61, 1-9

3 Fiedler, K. and Simons, K. (1994) Cell 77, 625-626

4 Lahtinen, U., Dahllöf, B. and Saraste, J. (1992) J. Cell Sci. 103, 321-333

5 Hauri, H.-P. and Schweizer, A. (1992) Curr. Opin Cell Biol. 4, 600-608

6 Schweizer, A., Matter, K., Fransen, J. A. M., Kreis, T. E., Ginsel, L. and Hauri, H.-P. (1990) Eur. J. Cell Biol. 53, 185-196

7 Lotti, L. V., Torrisi, M.-R., Pascale, M. C. and Bonatti, S. (1992) J. Cell Biol. 118, 43-50

8 Chavrier, P., Parton, R. G., Hauri, H.-P., Simons, K and Zerial, M. (1990) Cell 62, 317-329

9 Oprins, A., Duden, R., Kreis, T. E., Geuze, H. J. and Slot, W. J. (1993) J. Cell Biol. 121, 49-59

10 Pepperkok, R., Scheel, J., Hauri, H.-P., Horstmann, H., Griffiths, G. and Kreis, T. E. (1993) Cell 74, 71-82

11 Schweizer, A., Matter, K., Ketcham, C. M. and Hauri, H.-P. (1991) J. Cell Biol. 113, 45-54 
12 Banfield, D. K., Lewis, M. J., Rabouille, C., Warren, G. and Pelham, H. R. (1994) J. Cell Biol. 127, 357-371

13 Schweizer, A., Clausen, H., van Meer, G. and Hauri, H.-P. (1994) J. Biol. Chem. 269, 4035-4041

14 Saraste, J. and Svensson, K. (1991) J. Cell Sci. 100. $415-430$

15 Lippincott-Schwartz, J., Donaldson, J. G., Schweizer, A. et al. (1990) Cell 60, 821-836

16 Linstedt, A. D. and Hauri, H.-P. (1993) Mol. Biol. Cell 4, 679-693

17 Kappeler, F., Itin, C., Schindler, R. and Hauri, H.-P. (1994) J. Biol. Chem. 269, 6279-6281
18 Itin, C., Kappeler, F., Linstedt, A. D. and Hauri, H.-P. (1995) EMBO J. 14, 2250-2256

19 Trowbridge, I. S., Collawn, J. F. and Hopkins, C. R. (1993) Annu. Rev. Cell Biol. 9, 129-161

20 Letourneur, F. and Klausner, R. D. (1992) Cell 69 , 1143-1157

21 Fiedler, K., Parton, R. G., Kellner, R., Etzold, T. and Simons, K. (1994) EMBO J. 8, 1041-1047

22 Letourneur, F., Gaynor, E. C., Hennecke, S. et al. (1994) Cell 79, 1199-1207

Received 8 March 1995

\title{
Roles for microtubules and kinesin in membrane traffic between the endoplasmic reticulum and the Golgi complex
}

\author{
J. Lippincott-Schwartz and N. B. Cole
}

Cell Biology and Metabolism Branch, NICHD, NIH, Bethesda, MD 20892, U.S.A.

To gain insight into the mechanisms underlying the spatial organization and dynamics of intracellular membranes, we have focused on the roles of microtubules and microtubule motors in the translocation and positioning of membranes within the endoplasmic reticulum (ER)/Golgi system. The ER and Golgi exhibit remarkably different subcellular positions and morphologies, despite an intimate relationship in the generation, processing and sorting of lipid and protein. This is due in large part to their interaction with microtubules. Microtubules have long been known to serve as highways along which membranes travel throughout the cell. The slow-growing, or 'minus', ends of microtubules are usually localized at the microtubule organizing centre (MTOC) near the nucleus, while the fastgrowing, or 'plus', ends of microtubules radiate outwards towards the cell periphery. Organelles and their transport intermediates use this elaborate network to spatially segregate themselves, translocating toward the minus (inward) or plus (outward) ends of microtubules after attaching to them. The extensive array of interconnecting tubules comprising the ER extends plus-end-directed along microtubules to the cell periphery $[1-3]$, while stacks of Golgi cisternae actively cluster at the minus ends of microtubules at the MTOC $[4,5]$.

Abbreviations used: $\beta \mathrm{COP}, \beta$ subunit of coatamer complex; $\mathrm{BFA}, \mathrm{Brefeldin} \mathrm{A}$; endo $\mathrm{H}$, endoglycosidase $\mathrm{H} ; \mathrm{ER}$, endoplasmic reticulum; Man II, mannosidase II; MTOC, microtubule organizing centre; VSV G, vesicular stomatitis virus protein $\mathrm{G}$.
The required transport into the Golgi complex of newly synthesized proteins exported from the ER raises the question of exactly how membrane is transported between these two structurally and spatially distinct organelles. One obvious possibility is that they use microtubules to translocate into the central Golgi region. Previous work examining a role for microtubules in ER-to-Golgi transport has been inconclusive, however. Some studies have shown no effect of microtubuledisrupting drugs on transport of newly synthesized protein into the Golgi [6,7], while others have demonstrated varying degrees of inhibition [8-11]. To clarify the role, if any, of microtubules in ER-toGolgi transport, we examined the effect of the microtubule-disrupting agent, nocodazole, on the transport of the transmembrane viral glycoprotein vesicular stomatitis virus protein $\mathrm{G}$ (VSV G) in cells infected with the temperature-sensitive ts 045 strain of vesicular stomatitis virus [12]. At the restrictive temperature of $40^{\circ} \mathrm{C}$, VSV G is retained in the ER due to an inability to fold correctly. Upon lowering the temperature to $32^{\circ} \mathrm{C}$, VSV G folds correctly and rapidly exits the $\mathrm{ER}$, moving into the Golgi complex within 10-15 min, before its eventual delivery to the plasma membrane. The ability to follow a synchronized population of VSV G into the Golgi complex upon a decrease in the temperature makes VSV G an ideal marker for studying the ER-toGolgi pathway. Transport of VSV G into the Golgi in our studies was monitored both morphologically, using antibodies to VSV G, pre-Golgi and Golgi markers, and biochemically, by measuring the rate 